\title{
Detonation in Shocked Homogeneous High Explosives
}

\author{
C.S. Yoo \\ N.C. Holmes \\ P.C. Souers \\ This paper was prepared for submittal to the \\ Materials Research Fall Meeting \\ Boston, $M A$ \\ November 27-December 1, 1995
}

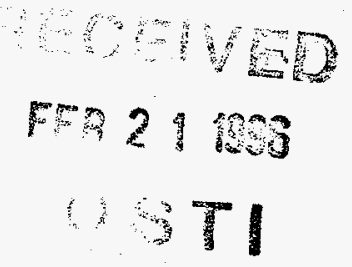

November 1995

Th is is a preprint of a paper intended for publication in a journal or proceedings. Since changes may be made before publication, this preprint is made available with the understanding that it will not be cited or reproduced without the permission of the author.

\section{DISCLAIMER}

This report was prepared as an account of work sponsored by an agency of the United States Government. Neither the United States Government nor any agency thereof, nor any of their employees, makes any warranty, express or implied, or assumes any legal liability or responsibility for the accuracy, completeness, or usefulness of any information, apparatus, product, or process disclosed, or represents that its use would not infringe privately owned rights. Reference herein to any specific commercial product, process, or service by trade name, trademark, manufacturer, or otherwise does not necessarily constitute or imply its endorsement, recommendation, or favoring by the United States Government or any agency thereof. The views and opinions of authors expressed herein do not necessarily state or reflect those of the United States Government or any agency thereof. 


\section{DISCLAIMER}

This document was prepared as an account of work sponsored by an agency of the United States Government. Neither the United States Covernment nor the University of California nor any of their employees, makes any warranty, express or implied, or assumes any legal liability or responsibility for the accuracy, completeness, or usefulness of any information, apparatus, product, or process disclosed, or represents that its use would not infringe privately owned rights. Reference herein to any specific commercial product, process, or service by trade name, trademark, manufacturer, or otherwise, does not necessarily constitute or imply its endorsement, recommendation, or favoring by the United States Government or the University of California. The views and opinions of authors expressed herein do not necessarily state or reflect those of the United States Government or the University of California, and shall not be used for advertising or product endorsement purposes. 


\section{DISCLAMMER}

Portions of this document may be illegible in electronic image products. Images are produced from the best available original document. 


\title{
DETONATION IN SHOCKED HOMOGENEOUS HIGH EXPLOSIVES
}

\author{
C. S. YOO, N. C. HOLMES, and P. C. SOUERS \\ Lawrence Livermore National Laboratory, University of California, Livermore, CA 94551, \\ yool@llnl.gov
}

\section{ABSTRACT}

We have studied shock-induced changes in homogeneous high explosives including nitromethane, tetranitromethane, and single crystals of pentaerythritol tetranitrate (PETN) by using fast time-resolved emission and Raman spectroscopy at a two-stage light-gas gun. The results reveal three distinct steps during which the homogeneous explosives chemically evolve to final detonation products. These are i) the initiation of shock compressed high explosives after an induction period, ii) thermal explosion of shock-compressed and/or reacting materials, and iii) a decay to a steady-state representing a transition to the detonation of uncompressed high explosives. Based on a gray-body approximation, we have obtained the $C J$ temperatures: $3800 \mathrm{~K}$ for nitromethane, $2950 \mathrm{~K}$ for tetranitromethane, and $4100 \mathrm{~K}$ for PETN. We compare the data with various thermochemical equilibrium calculations. In this paper we will also show a preliminary result of single-shot time-resolved Raman spectroscopy applied to shock-compressed nitromethane.

\section{MOTIVATION}

In contrast to better known macroscopic properties of high explosives (HEs), the energetic processes are poorly understood at an atomistic and/or molecular level. The detonation velocity, particle velocity, energetics of detonation, detonation products, thermal decomposition, material parameters controlling chemical sensitivity, etc, have well been explored for many energetic molecules. However, it is poorly understood even for a relatively simple system like nitromethane, how thermal shock energy transfers to HE molecules and dissipates through phonons and vibrons of $\mathrm{HE}$ lattice, what kind of transients are initially generated, and how these species evolve and eventually lead to detonation.

Plane shock wave experiments provide a well controlled way of investigating high explosives at well characterized shock states. Combined with time-resolved measurements, they provide an unque opportunity to monitor the changes in HE during detonation. The emphasis of shock wave research in the past, however, has been on understanding the continuum or bulk properties of $\mathrm{HE}$ such as detonation velocities, particle velocities, and burn rates. Although various thermochemical and phenomenological models have been developed to infer these measurements [1], obtaining the description of detonation at a molecular level still remains a challenging problem. This is in part due to the lack of information regarding chemical species and kinetics associated with detonation. Therefore, a logical approach to this problem is a shock-wave experiment combined with fast timeresolved spectroscopy, being capable of characterization of various short lived transients and their kinetics [2-4]. Furthermore, the recent advances in computational capability make such an understanding of detonation in microscopic details feasible to obtain.

The goal of this study is to get new physical insight into shock initiation and detonation chemistry by using fast time-resolved emission and Raman spectroscopy at a two-stage light-gas gun. The density, particle size, pores, defects, etc, strongly affect the energetics of HE processes. However, they often interfere with the events that are intrinsic to HE molecules. For example, the previous study performed in shocked HE powders [4] showed strong emission from voids and grain boundaries, rather than from HE molecules or transients that were in high density states. Therefore, this study will be performed in several homogeneous high explosives that minimize such effects, including nitromethane (NM), tetranitromethane (TNM), and single crystals of pentaerythritol tetranitrate (PETN). 


\section{SCIENTIFIC ISSUES IN DETONATION}

Detonation in high explosives can be classified into three steps based on their spatial and temporal characteristics. (1) The primary step of thermal excitation and vibrational energy transfer. This process occurs in a sub-ps to one ns regime and proceeds in a highly non-equilibrium manner. During this period, hot spots are formed and highly vibrationally excited HE molecules dissociate to form transient species [5]. (2) The second step is one in which chemical kinetics of the primary species dominate. In this period, one to several $100 \mathrm{~ns}$, the primary species strongly interact with each other and, as a result, they either recombine together or form the secondary products. The latter case typically proceeds exothermically in many energetic molecules. (3) Finally, the propagation step where the exothermic reaction eventually leads to detonation. In this period, $\sim \mu$ s, the final detonation products are created, and the chemical equilibrium is achieved.

The primary detonation process, energy transfer and vibrational relaxation, occurs on a ps time scale. In the case that a fast $(\sim 5 \mathrm{Km} / \mathrm{s})$ propagating shock wave thermally pumps $\mathrm{HE}$ molecules, the initiation reaction would then be completed within approximately 100 -molecular layer determining the shock front. The mechanisms for energy transfer and vibrational activation in this region can be characterized by fast spectroscopy with a ps time resolution and be directly compared with theoretical results such as a molecular dynamics simulation carried out over the thickness of the shock front [6]. However, because these processes are completed within a $50 \mathrm{~nm}$ molecular layer, an order of the diffraction limit of visible light, shock wave measurements should be performed in thin films to avoid a dynamic uncertainty. A consequence is then the lack of any observable signal during the single, transient shock-wave event.

Detonation products of high explosives are reasonably well understood based on recovery experiments, bomb calorimetric measurements, and thermochemical analyses [7]. However, it is not so well understood how high explosive molecules evolve in time to final detonation products, a crucial issue that should be addressed for understanding shock-initiation as well as for engineering new energetic materials. For example, in a relatively simple high explosive like nitromethane, there have been at least six different mechanisms previously reported to explain how nitromethane initiates the energetic process, as summarized in Fig 1 [8-13]. They range from dimerization, a concerted type reaction mechanism typically occurring in condensed matter, to dissociation, a gas phase reaction. It simply reflects the infancy of our understanding of detonation in a molecular level. Obviously, the first step to this problem is to identify chemical species produced during the initiation period and to model the reaction in terms of the first principles in physics and chemistry such as $a b$-initio quantum chemical calculations. The kinetic measurements should be followed and the molecular based reaction models be developed.

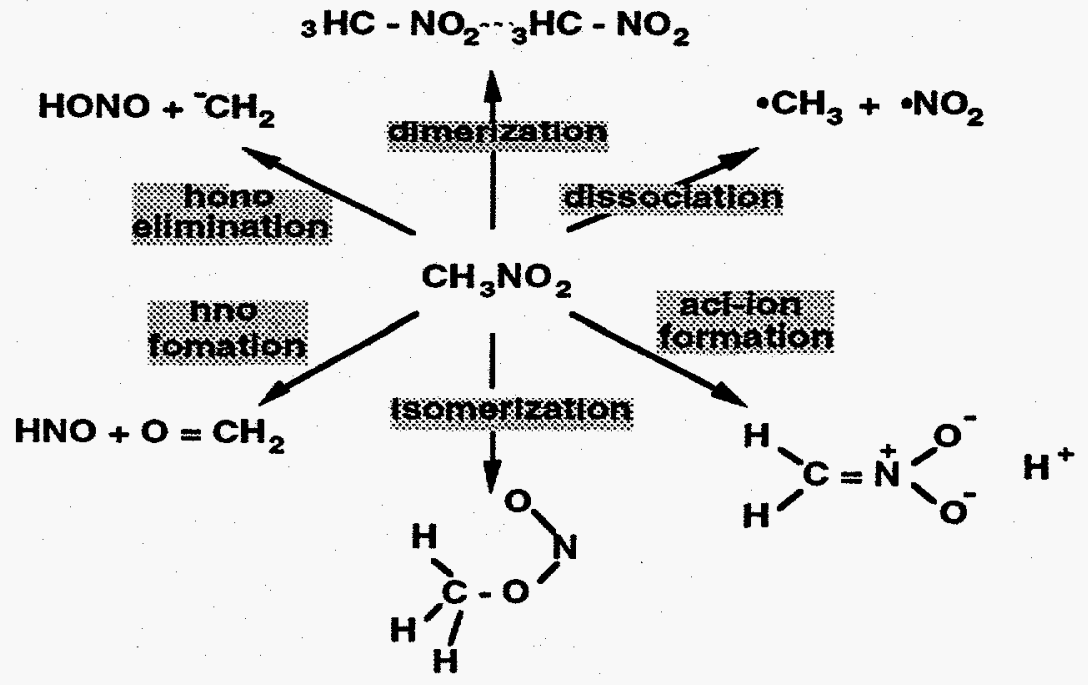

Figure 1. Various initiation reactions proposed for nitromethane at high pressures and temperatures. 
Shock wave research on high explosives to date has been concentrated more on understanding the third propagation process. The energetics of these processes are relatively well known in many explosives, including the von-Neumann spike and $C-J$ conditions, detonation wave velocity, material velocity, and thermochemical description of detonation. The detonation is traditionally conceived with the assumption of "thermal and chemical equilibrium". Neither is this assumption true in many cases, nor it is sufficient enough to appropriately describe the processes associated with the performance of high explosives. For example, most of thermochemical equilibrium models fail to describe the detonation velocity in many high explosives, particularly insensitive carbon-rich systems due to the effects like carbon coagulation [14]. Therefore, it is important to understand the mechanisms and kinetics for pre-, during, and post-detonation processes. In the next section, we show time-resolved temperature measurements in detonating high explosives, providing information on detonation kinetics. We then also show our preliminary results of singleshot time-resolved spontaneous Raman spectroscopy performed on shock compressed nitromethane.

\section{SHOCK TEMPERATURES BY TIME-RESOLVED EMISSION SPECTROSCOPY}

The shock temperature of high explosives is important for understanding shock-initiation and detonation processes; however, it has been one of less frequently measured thermodynamic variables. On the other hand, unlike other variables including pressure, volume, and energy, temperature strongly depends on thermochemical models which require experimental verification.

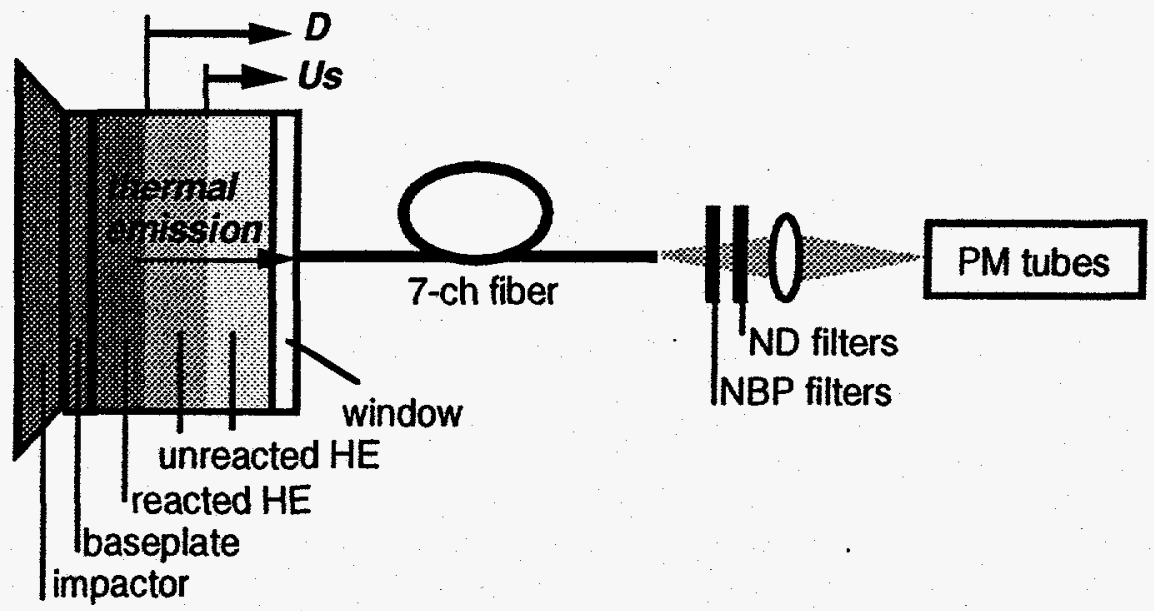

Figure 2. The experimental setup for time-resolved shock temperature measurements of transparent homogeneous high explosives.

Figure 2 shows the experimental setup to measure time-resolved temperatures of shockcompressed high explosives. The sample in a 6-8 $\mathrm{mm}$ thick cavity between a baseplate and a transparent window is compressed by using a two-stage gas-gun which can accelerate an impactor up to $8 \mathrm{~km} / \mathrm{s}$. Thermal emission from shock-compressed high explosive is time-resolved by using six photomultiplier tubes for which spectral windows (40 nm bandwidth) are set in the spectral range between 350 and $700 \mathrm{~nm}$ by using narrow beam pass filters. In this setup, thermal emission is collected from the central $3 \mathrm{~mm}$ area of HE, limited by the acceptance cone of an optical fiber bundle [15]. This results in fast time resolution, a few ns, primarily depending on the rise time of recording electronics. The temperature of the high explosive is then obtained by fitting this timeresolved thermal emission data to a gray body Planck function at $1 \mathrm{~ns}$ intervals during the event of interest, typically one $\mu \mathrm{s}$ long.

Figure 3 shows the time-resolved temperatures of NM, TNM, and (110) PETN single crystal [16] shocked to $10.7,12.9$ and $13.3 \mathrm{GPa}$, respectively. The temporal profiles can be characterized into i) a predetonation zone showing initial increases in temperature, ii) a superdetonation zone 
showing rapid temperature increases to the peak values, and iii) a normal detonation zone showing temperature decreases to steady state values.

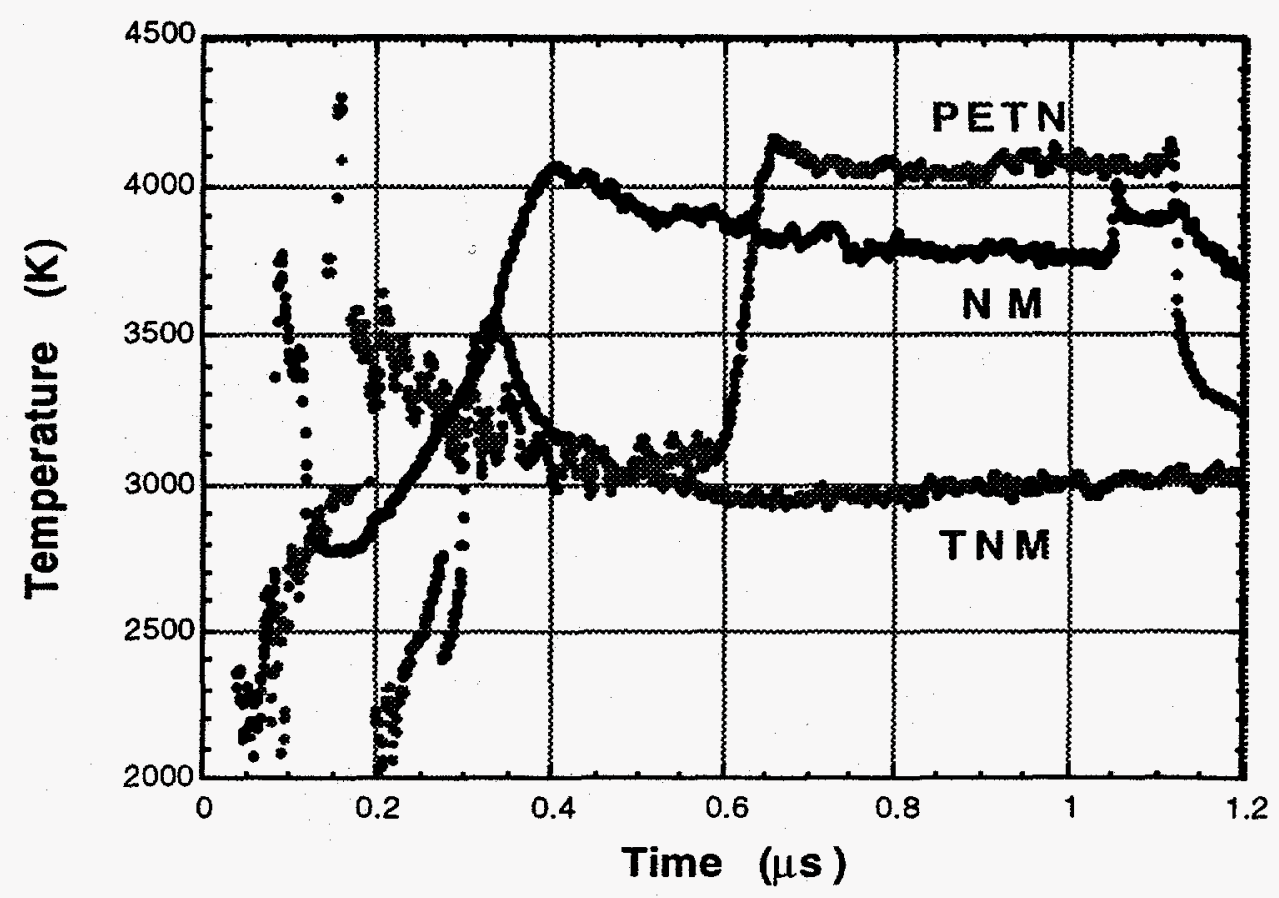

Figure 3. Time-resolved shock temperatures of selected homogeneous high explosives.

The temperature changes in Fig 3 can be understood in the context of the thermal explosion model $[17,18]$. In homogeneous high explosives, the reaction is believed to initiate behind the shock front near the baseplate/HE interface as shown in Fig 2. This means that the detonation initially occurs from shock-compressed high explosives (superdetonation) and, then, from uncompressed high explosives (normal detonation) as the detonation front catches the shock front. Figure 4 illustrates various thermodynamic states through which homogeneous high explosive molecules evolve during detonation.

The initial shock state, $i$, is defined by the impedance match between an impactor and unreacted HE. The pressure of this shocked but unreacted HE increases to the von-Neumann spike, $S^{*}$, by chemical energy release behind the shock front. The chemical reaction initiates at $S^{*}$, and the products eventually evolve to the $C J^{*}$ state as the reaction is fully developed. These detonation products then expand isentropically to the condition matching the impedance of the impactor $k$, as long as the reaction front remains behind the shock front. At a later time, however, the detonation front catches the shock front, and the detonation occurs directly from unshocked $\mathrm{HE}$ at $S$, and the products evolve to the $C J$ state and to the impedance match condition, $j$, between the isentropically expanded $\mathrm{HE}$ products and the impactor.

The temperature, on the other hand, increases as the reaction progresses and peaks at the $C J$. The opacity of the reaction products is substantially higher than that of unreacted high explosive due to formation of graphite and other hydrocarbons at high temperatures [20]. Under these conditions thermal emission measured across the reaction zone (Fig 2) is mostly from the reaction front, and the measured temperatures in Fig 2 can be correlated to those at various thermodynamic states in Fig 4. The temperature will initially increase to that at $S^{*}$ during predetonation and then to the $C J^{*}$ temperature of superdetonated products as the exothermic chemical reaction fully develops. The $C J^{*}$ temperature then further decays to the $C J$, as the detonation front catches the shock front. The temperature should then remain at the $C J$, as long as the impact condition is at' or below the $C J$ condition. The temperature changes observed in Fig 3 are clearly consistent with this model. 


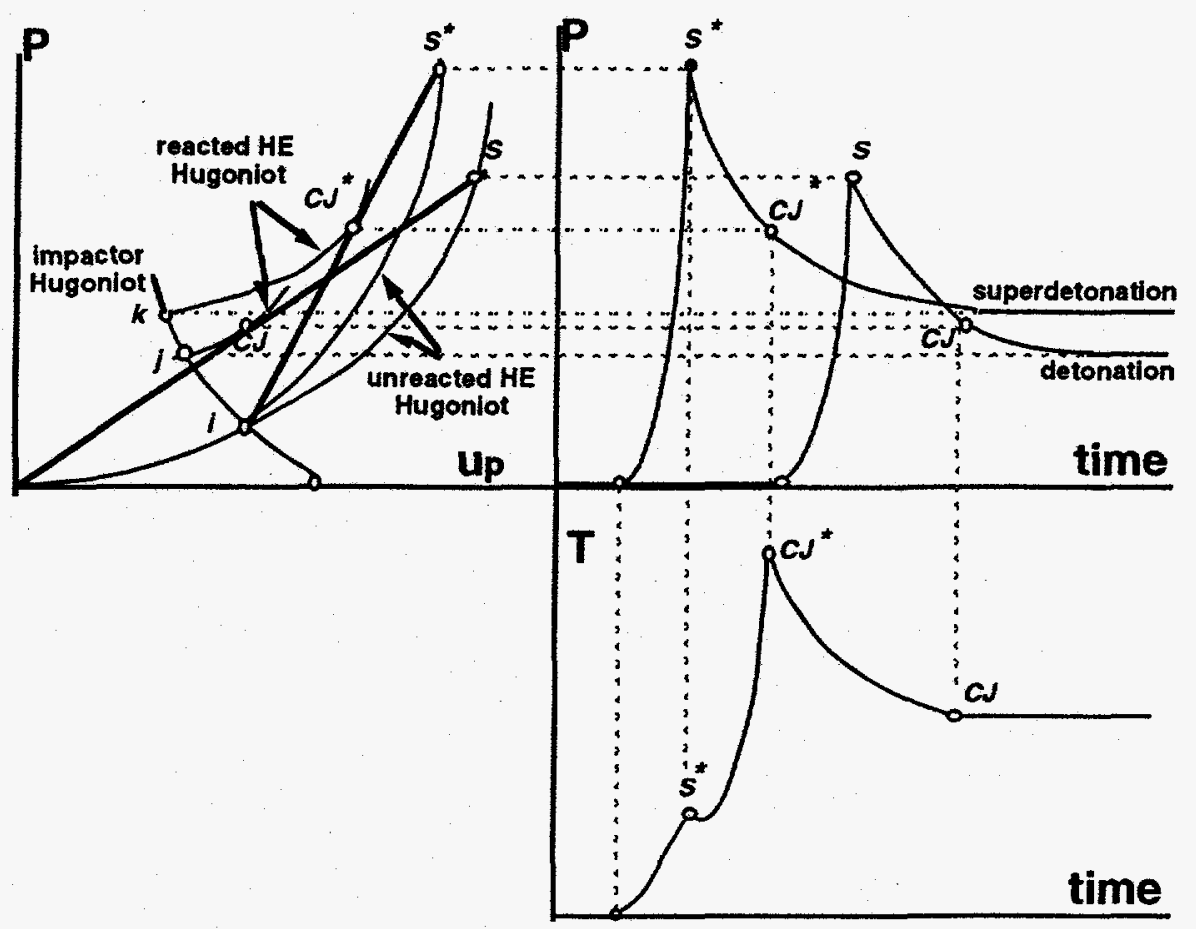

Figure 4. Thermodynamic states of the shock-compressed homogeneous high explosive and its reaction products, together with the pressure and temperature changes at the reaction front.

The $C J$ temperatures of these explosives can be obtained from the steady-state values in Fig 3 as discussed above. The results are summarized in Table $\mathrm{I}$, together with the calculated $C J$ temperatures using themochemical equilibrium codes for comparison. Clearly, the calculated temperatures are sensitive to various models, and the current data could provide critical constraints for various models. The $C J$ temperature of PETN is higher than other two due to the abundance of oxygen. The $C J$ temperature of TNM is substantially lower than that of NM, likely due to the absence of hydrogen in TNM. It is also noticed that, unlike TNM and NM, PETN detonates at substantially lower pressures than the $C J$ pressure near $31 \mathrm{GPa}$, consistent with the previous observation that PETN is sensitive along the (110) direction [21].

Table I. The steady-state temperatures of shock compressed homogeneous high explosives in comparison with the calculated $C J$ temperatures [19].

\begin{tabular}{lcccccccc}
\hline & \multicolumn{2}{c}{ Pressure (GPa) } & & \multicolumn{5}{c}{ Temperature (K) } \\
\cline { 2 - 6 } \cline { 5 - 8 } & unreacted & reacted & & Measured & CHEQ & CHEETA & BKWR & JCZ3 \\
\hline NM & 107 & 128 & & 3800 & 3750 & 3000 & 3000 & 3400 \\
TNM $^{1}$ & 129 & 137 & & 2950 & 2640 & 2700 & 2200 & 2500 \\
PETN $^{2}$ & 133 & 191 & & 4100 & 4430 & 4300 & 3300 & 4200
\end{tabular}

1. TNM used in the experiments is $98 \%$ pure. The CHEQ and CHEETA calculations were also done in a mixture of $98 \%$ TNM and $2 \%$ NM.

2. (110) PETN single crystals were used. 


\section{DETONATION KINETICS BY SHOCK TEMPERATURES}

In addition to the $C J$ temperature, the shock temperature data also provides information regarding the detonation kinetics. It is evident from Fig 3 that neither shock initiation nor detonation occurs instaneously. There is a relatively long induction period for HE to initiation; for example, the shock-initiation takes about $50 \mathrm{~ns}$ for NM and PETN and $200 \mathrm{~ns}$ for TNM. The transitions to the $C J{ }^{*}$ states occur in 20-50 ns in TNM and PETN but in $200 \mathrm{~ns}$ in NM. The peak temperatures then approach the steady-state values for the next 100-400 ns, representing the transition to detonation in uncompressed high explosives. The temporal structure of this measured temperature is now subject to the analysis by using various chemical models such as a reaction flow model [22].
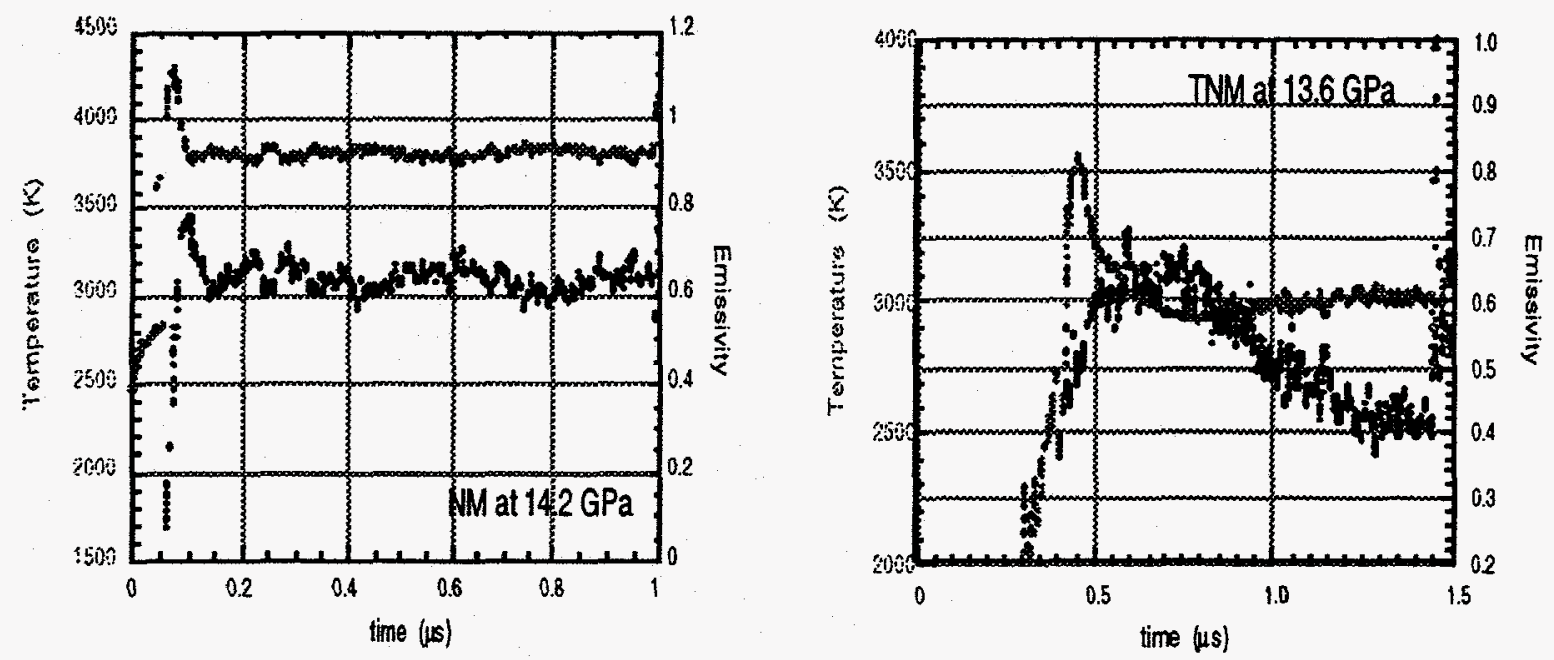

Figure 5. The emissivity changes of shock compressed NM and TNM, together with their temperature changes.

In addition to the complicated structure in the predetonation period, there is an evidence for a weak time-dependent change in the post detonation period, long after the reaction is fully developed in TNM. This can be illustrated more clearly in the emissivity change. Figure 5 shows the emissivity changes in NM and TNM during detonation, plotted with respect to their temperature changes. The emissivity of NM reaches to a steady-state value after the initial rise, similar to the temperature change. A similar behavior of emissivity was observed in most of other experiments of NM and PETN single crystals. However, the emissivity change in TNM is quite different from those of NM and PETN. It increases to the peak value rather slowly and then decreases continuously for the next several $100 \mathrm{~ns}$. This result implies that chemical changes occur even at long times, $\sim 500 \mathrm{~ns}$, after the detonation.

Similar non-equilibrium changes in post-detonation have also been previously recognized in insensitive high explosives [23] and have been conjectured to be due to carbon coagulation in carbon rich systems. The nucleation and growth of carbon particles typically takes several $100 \mathrm{~ns}$ to one $\mu$ s time period [14,20]. However, because TNM is a carbon difficient system and is believed to form no carbon particles based on thermochemical calculations [19], we believe it is not the case of TNM. Therefore, the nature of this postdetonation process in TNM is not known. On the other hands, one may conjecture other possibilities, including phase separation [24] and/or chemical decomposition [25] of final detonation products, $\mathrm{CO}_{2}, \mathrm{H}_{2} \mathrm{O}$, and $\mathrm{N}_{2}$, at high pressures and temperatures. Clearly, further experimental and theoretical studies are needed to clarify this important issue. 


\section{SHOCK INTTIATION BY TIME-RESOLVED RAMAN SPECTROSCOPY}

The chemistry of shock compressed high explosives starts well before the detonation, typically a few $10-100$ ns after being shocked (see Fig 3). In order to understand the predetonation chemistry, it is necessary to characterize transient species, reaction pathways, and kinetics, all of which may be obtained by using fast time-resolved Raman spectroscopy. The experimental setup for measuring time-resolved Raman scattering, shown in Fig 6, is similar to those used in the previous studies performed in the stepwised shock-wave loading experiments [26,27]. However, in the present study the experiments are designed to obtain time-resolved Raman data at the onset of detonation in single shock-compressed high explosives by using a 2-stage gas-gun. Details regarding the experimental setup will be presented elsewhere.

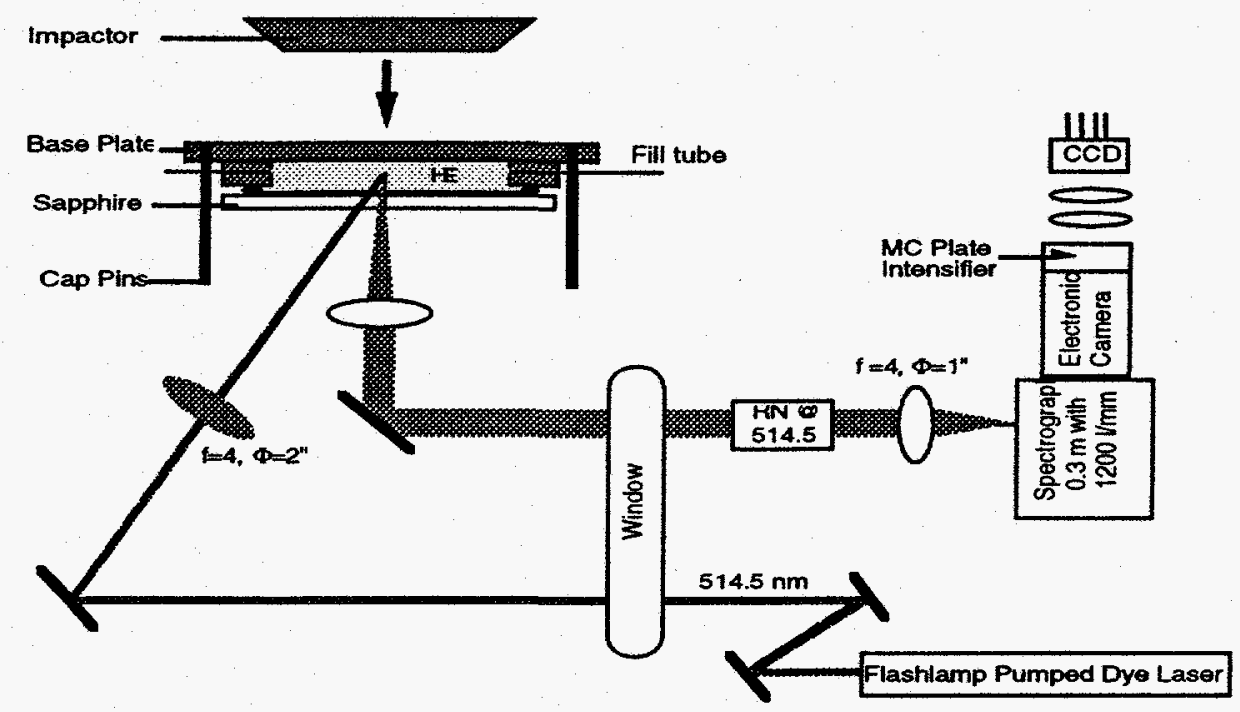

Figure 6. Single-shot time-resolved spontaneous Raman spectroscopy for detonating high explosives.

Preliminary Raman data from pure nitromethane shocked to $9.8 \mathrm{GPa}$ is shown in Fig 7, as recorded on a 2-D multichannel plate intensifier. Five sharp vibrational features of $\mathrm{NM}, \delta_{\mathrm{s}}\left(\mathrm{NO}_{2}\right)$ at $655 \mathrm{~cm}^{-1}, v(\mathrm{CN})$ at $917 \mathrm{~cm}^{-1}, \delta_{\mathrm{s}}\left(\mathrm{CH}_{3}\right)$ at $1379 \mathrm{~cm}^{-1}, v_{\mathrm{s}}\left(\mathrm{NO}_{2}\right)$ at $1402 \mathrm{~cm}^{-1}$, and $\mathrm{v}_{\mathrm{a}}\left(\mathrm{NO}_{2}\right)$ at 1561 $\mathrm{cm}^{-1}$, are evident, together with other broad features, which form the background and mostly arise from thermal emissions of NM. The pressure induced shifts toward the red are small but evident at least for three major bands, $v(\mathrm{CN}), \delta_{\mathrm{s}}\left(\mathrm{CH}_{3}\right)$, and $v_{\mathrm{s}}\left(\mathrm{NO}_{2}\right)$. The red shifts, "mode hardening", observed in this study range from $1.0 \mathrm{~cm}^{-1} / \mathrm{GPa}$ in $v(\mathrm{CN})$ to $1.5-2.0 \mathrm{~cm}^{-1} / \mathrm{GPa}$ in $\delta_{\mathrm{S}}\left(\mathrm{CH}_{3}\right)$ and $v_{s}\left(\mathrm{NO}_{2}\right)$. These shifts are consistent with the previous single shock data [28], but are substantially smaller than that observed in the step-wise loading experiments [27]. It is probably because the step-wise loading results in substantially lower temperature and higher volume compression than the single shock loading to the same peak pressure.

The background in Fig 7 rapidly increases at approximately 200 ns after NM being shocked, $t_{n}$, but disappears as the laser intensity diminishes. It is also noted that the intensity of this broad feature is substantially higher at shorter wavelengths toward the laser wavelength at $514.5 \mathrm{~nm}$. Therefore, this feature is not due to thermal emission, but is likely due to the elastic scattering or laser induced fluorescence, both of which could arise from chemical reaction of NM and/or transients. The disappearance of $v(\mathrm{CN})$ and the background enhancement were also observed previously in the sensitized NM experiments and were attributed to the $\mathrm{CN}$ bond scission and the fluorescence from transient species, respectively [27]. 


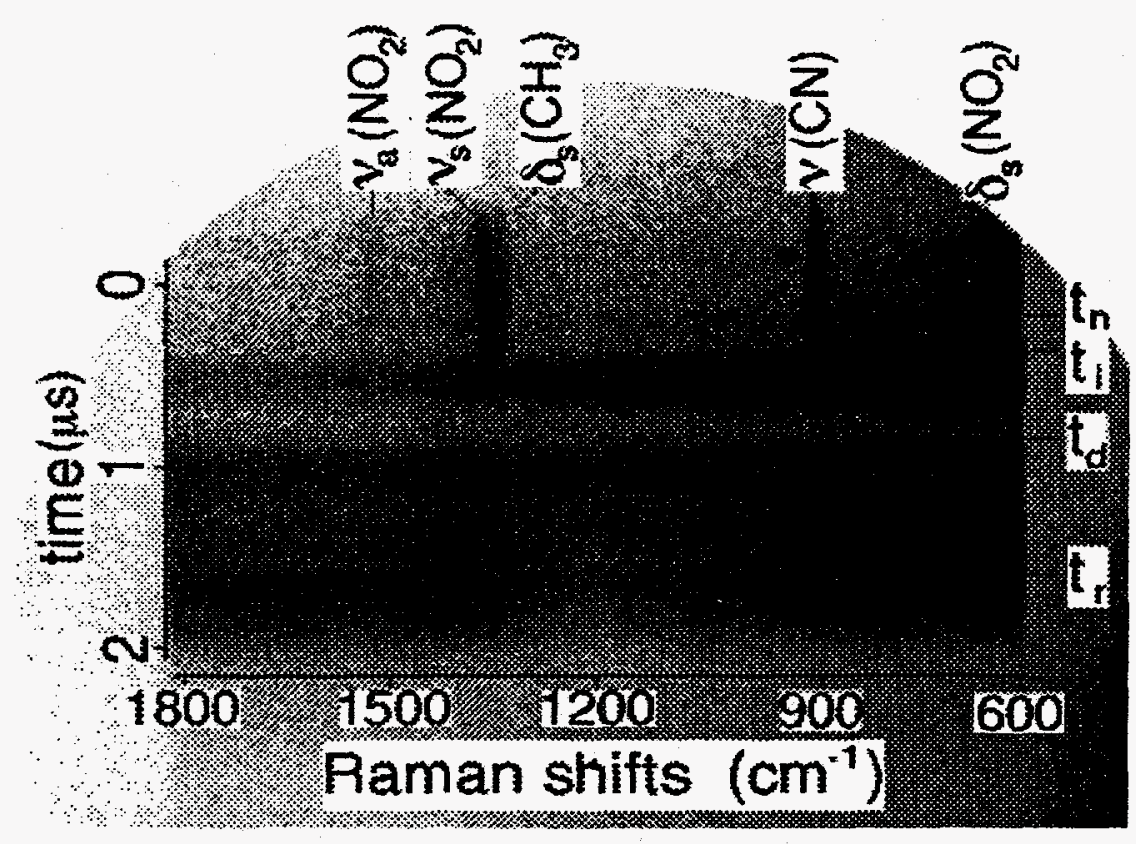

Figure 7. Raman scattering data of nitromethane shocked to $9.8 \mathrm{GPa}$. Various events $\mathrm{t}_{\mathrm{n}}, \mathrm{t}_{\mathbf{i}}, \mathrm{t}_{\mathrm{d}}, \mathrm{t}_{\mathrm{r}}$, respectively, indicate the shock arrival at NM, initiation, detonation, and reshock time.

\section{CONCLUSION}

Understanding detonation chemistry requires advances in both experiments and theory. We have demonstrated that shock wave experiments combined with time-resolved spectroscopy are useful to study the shock initiation and detonation in homogeneous high explosives. In addition to the capability measuring the $C J$ temperature accurately, time-resolved emission spectroscopy also reveals the detonation kinetics, crucial for developing new theoretical reaction models. The kinetics in the predetonation period are complicated and depend strongly on pressure, temperature, time, and initiation reactions. We also found an indication of non-equilibrium behavior of TNM in the postdetonation period. The studies on shock-initiation are currently under way by using timeresolved Raman spectroscopy at a two-stage gas-gun.

\section{ACKNOWLEDGMENTS}

We thank Ervin See, Jim Crawford and Bruce Morgan at LLNL for the technical assistance. We also appreciate J. Dick at LANL for providing the PETN single crystals and for comments valuable to the study. The discussions with $S$. Sheffield at LANL and B. Nellis, D. Erskine, F. Ree and M. van Thiel at LLNL were very useful for the study. This work was performed under auspices of the U.S. DOE by the LLNL.

\section{REFERENCES}

1. R. Cheret, Detonation of Condensed Explosives (Springer-Verlag, New York, 1993).

2. Y.M. Gupta, J. De Phys. IV, C4-345, (1995). 
3. D.S. Moore and S.C. Schmidt, Shock Waves in Condensed Matter-1987.S.C. Schmidt and N.C. Holmes, Eds. (North-Holland, Amsterdam, 1988), pp 35.

4. A.M. Renlund and W.M. Trott, ibid, pp. 547.

5. D.D. Dlott and M.D. Fayer, J. Phys. Chem. 92, 3798 (1990).

6. D.W. Brenner, D.H. Robertson, M.L. Elert, and C.T. White, Phys. Rev. Lett. 70, 2174 (1993).

7. P.C. Souers and J.W. Kury, Propellants. Explosives, Pyrotechnics 18, 175 (1993).

8. S.A. Sheffield, R. Engelke, and R.R. Alcon, In-situ study of the chemically driven flow field in initiating homogeneous and heterogeneous nitromethane explosives in Proceedings of the Ninth International Symposium on Detonation, pp39, Portland, Oregon (1989).

9. R. Engelke, L.E. William, and C.M. Rohlfing, J. Phys. Chem. 90, 545 (1986).

10. C.F. Melius, J. de Physique, C4-341 (1987).

11. J.J. Dick, J. Phys. Chem. 97, 6195 (1993).

12. C.P. Constantinou, J.M. Winey, and Y.M. Gupta, J. Phys. Chem. 98, 7767 (1994).

13. C.J. Piermarini, S. Block and P.J. Miller, J. Phys. Chem. 93, 457 (1989).

14. M.S. Shaw and J.D. John, Shock Waves in Condensed Matter-1987, S.C. Schmidt and N.C. Holmes, Eds. (North-Holland, Amsterdam, 1988), pp. 503.

15. N.C. Holmes, Rev. Sci. Instru. 66, 2615 (1995).

16. PETN single crystals oriented to (110) plane were obtained from J. Dick at the LANL. In the present experiments, shock wave propagates to the direction perpendicular to the (110) plane.

17. A.W. Campbell, W.C. Davis, J.B. Ramsey, and T.R. Travis, Phys. Fluid 4, 511 (1961).

18. D.R. Hardesty, Combustion and Flame 27, 229 (1976).

19. M. van Thiel, F.H. Ree, and L.C. Haselman, Accurate Determination of Pair Potentials for a CwHxNyOz system of Molecules: a Semiempirical Method, UCRL-ID-120096, LLNL (March, 1995).

20. N.C. Holmes, Rev. Sci. Inst. 64, 357 (1993).

21. J.J. Dick, R.N. Mulford, W.J. Spencer, D.R. Pettit, E. Garcia, D.C. Shaw, J. Appl. Phys. 70, 3572 (1991).

22. C.M. Tarver, Combustion and Flame 46, 157 (1982).

23. A.N. Dremin, S. Savrov, and A.N. Amdrievskii, Comb. Expl. and Shock Waves, vol.1, 1965, pp 1.

24. F.H. Ree, J. Chem. Phys. 84, 5845 (1986). 
25. M.L. Japas and E.U. Frank, Ber. Bunsenges. Phys. Chem. 89, 793 (1985).

26. C.S. Yoo, Y.M. Gupta, and P.D. Hom, Chem. Phys. Letts. 159, 178 (1989).

27. G.I. Pangilian and Y.M. Gupta, J. Phys. Chem. 98, 4522 (1994).

28. A.M. Renlund and W.M. Trott, Shock Waves in Condensed Matter- 1989, S.C. Schmidt, J.N. Johnson, and J.W. Davison, Eds. (Elsevier Science Pub; New York, 1990) pp 875. 